\title{
Enhanced Heat Release Analysis for Advanced Multi- Mode Combustion Engine Experiments
}

Elliott A. Ortiz-Soto ${ }^{\mathrm{a},{ }^{*},}$, George A. Lavoie ${ }^{\mathrm{a}}$, Jason B. Martz ${ }^{\mathrm{a}}$, Margaret S. Wooldridge ${ }^{\mathrm{a}, \mathrm{b}}$, and Dennis N. Assanis ${ }^{\mathrm{c}}$

${ }^{\mathrm{a}}$ Department of Mechanical Engineering, University of Michigan, Ann Arbor, Michigan 48109-2125, USA

${ }^{b}$ Department of Aerospace Engineering, University of Michigan, Ann Arbor, MI 48109-2125, USA

${ }^{c}$ Department of Mechanical Engineering, Stony Brook University

Stony Brook, NY 11794-2300

*Corresponding Author

University of Michigan

Department of Mechanical Engineering

1231 Beal Ave., Ann Arbor, Michigan, USA 48109-2133

Tel: 734-764-2694, Fax: 734-647-3170,

E-mail address: eortizso@umich.edu 


\section{Abstract}

Advanced combustion strategies, such as Homogeneous-Charge Compression-Ignition (HCCI) and Spark-Assisted HCCI or Spark-Assisted Compression-Ignition (SACI) hold considerable promise for improving engine efficiencies while maintaining low pollutant emissions, yet few models exist that accurately include the important chemical and physical mechanisms of these advanced combustion strategies. Further, experimental data from advanced combustion engine experiments are not well represented using conventional spark ignited analytical tools. This paper presents new methods for advanced combustion analysis that integrate previous analytical methods with new algorithms to capture the unique features of advanced combustion strategies like SACI.

The new analytical capabilities were incorporated into a program which was designated the Advanced Combustion Engine Heat Release Analysis (ACE-HRA) tool. The models developed and applied in ACE-HRA were assessed by comparison with high fidelity engine simulations of HCCI and SACI. The high fidelity simulations provided data sets with detailed predictions of heat release rates, temperatures, auto-ignition timing, flame speeds and other key parameters not resolved or measured in engine experiments. The sensitivity of ACE-HRA estimates to model input data was quantified for important engine performance parameters. The sensitivity analysis showed that estimates for in-cylinder masses have the largest overall impact on the ACE-HRA results (e.g. $\pm 10 \%$ variation led to changes on the order of $\pm 5-10 \%$ in peak rate of heat release, burn duration and peak temperature). Noticeable differences in peak heat release rate and ringing intensity were also observed when comparing cycle-by-cycle analysis against ensemble-average analysis, which has implications on how the results are interpreted and applied in modeling work.

After validating ACE-HRA with the high-fidelity simulations, ACE-HRA was applied to interpret the data from a recent experimental study of SACI combustion. The ACE-HRA methods were used to infer the effects of flame propagation on in-cylinder gradients and cycleto-cycle variability, and to provide quantitative estimates for the associated changes in the endgas burn rate. The trends observed, such as the decrease in burn rate for later auto-ignition and higher burn fraction by flame, provide more in-depth understanding of SACI combustion and demonstrate the insight that can be revealed by the new ACE-HRA tool. 


\section{Keywords}

advanced internal combustion engines; experimental heat release analysis; HCCI, SACI, SI; heat transfer; flame propagation; auto ignition 


\section{Introduction}

Advanced combustion strategies, such as Homogeneous-Charge Compression-Ignition (HCCI) and Spark-Assisted HCCI (SA-HCCI) or Spark-Assisted Compression-Ignition (SACI), are important methods to improve internal combustion engine efficiency and emissions. HCCI combustion relies on chemically controlled auto-ignition [1-4], and can be operated with much leaner mixtures, higher compression ratios and un-throttled, considerably increasing thermodynamic efficiency compared to conventional spark-ignition (SI). However, the HCCI operating range is limited by high pressure-rise rates due to rapid combustion events, and stability issues resulting from the lack of a direct ignition trigger. SA-HCCI or SACI is a twostage, hybrid advanced combustion mode, which uses spark-ignition and flame propagation to directly initiate or stimulate the occurrence of auto-ignition and HCCI-like combustion [5-7]. SACI allows for combustion under conditions not possible when exclusively using SI or HCCI. SACI can also be used to reduce peak heat release rates. Experimental studies have confirmed the viability of SACI and have suggested potential operating strategies (e.g. [8,9]). Conceptual studies have also demonstrated that sizable vehicle fuel economy gains, between $23 \%$ and $58 \%$, are achievable if SACI can be effectively implemented [10].

Optimization of HCCI and SACI methods requires improved understanding of the important combustion processes. Heat release analysis is an essential tool for interpreting experimental pressure data from HCCI, SACI and conventional spark ignition (SI) strategies, and heat release analysis of experimental data provides key inputs for model development and validation. Heat release analysis typically follows a regressive modeling approach, where the measured incylinder pressure, combustion efficiency and estimated trapped masses are used to calculate the mean gas temperature, composition, and combustion heat release.

Many frameworks for cylinder pressure analysis of different levels of complexity have been presented in the literature over years, and have demonstrated good success for evaluating conventional SI and diesel engine combustion [11-18]. The introduction of advanced combustion strategies, particularly approaches that used mixed-modes of combustion like SACI, which

combines flame propagation with auto-ignition, and other unconventional engine operating strategies motivates the development of new analytical methods to understand and optimize these combustion modes. 
This paper describes new methods to analyze experimental pressure data and extract information on heat release. The approach integrates previous analytical methods to estimate important combustion parameters (such as global heat release, gas properties, and estimates of residual mass) with new algorithms to capture the unique features of advanced combustion strategies like SACI, including unconventional valve strategies, elevated dilution levels, and multi-mode combustion regimes. Specifically, the current work presents methods developed to estimate autoignition timing, fractions of heat release by flame propagation and by auto-ignition, auto-ignition heat release rates, and end-gas/post-flame thermodynamic states. The methods were incorporated into a MATLAB framework and the approach is called Advanced Combustion Engine Heat Release Analysis (ACE-HRA). The ACE-HRA was validated by comparison with computational data from closed-cycle high fidelity simulations (KIVA) for HCCI and SACI combustion modes. Sensitivity analysis on key parameters was performed to assess the sensitivity of the results to uncertainties in the input parameters, including the type of ensemble analysis used, engine geometry data, pre-conditioning methods used with the experimental pressure data, and the type of thermodynamic and combustion models used. The utility of ACE-HRA for experimental analysis and model development of multi-mode combustion is then demonstrated using experimental data from a recent SACI engine study.

\section{Modeling Approach for Evaluating Advanced Combustion Engine Data}

The new models and methods developed in this work include a two-zone thermodynamic model to estimate the states of the end-gas and post-flame regions, semi-empirical methods for estimating auto-ignition timing and multi-mode burn fractions, and a modified heat transfer model to account for the simultaneous presence of auto-ignition and flame propagation during SACI combustion. The computational approach used for each of these combustion parameters is described in the following sections. Well-established methods were used to estimate combustion heat release, trapped in-cylinder mass, and gas properties. The integration of the new approach with the established methods is also described in this section. 


\subsection{Two-Zone Thermodynamic Model for Advanced Multi-Mode Combustion}

A novel conceptual representation for multi-mode combustion including SI, HCCI and SACI has been devised for this work. The physical model is based on the standard two-zone assumption for flame propagation $[13,15,19,20]$ with auto-ignition in the end-gas zone, as shown conceptually in Figure 1. The two-zone model is used to establish the physical mathematical framework for the advanced combustion analysis methods, including heat transfer, auto-ignition timing, multimode burn fractions, end-gas temperature and laminar flame speeds.

The physical model is summarized as follows. At the time of spark, the fuel-air-diluent charge in the cylinder is divided into two zones: the end-gas zone and the post-flame zone. The post-flame zone contains all the mass that has been consumed by the flame, transferred from the end-gas at a rate determined by flame propagation. The flame is considered a constant pressure combustion process, which is constrained to an infinitely thin interface dividing the zones. The species in the post-flame zone are assumed to be at chemical equilibrium based on the pressure and temperature in the post-flame zone. The end-gas is initially unreacted, but as the temperature increases during compression by the piston and due to flame propagation, auto-ignition chemistry converts the unburned species into combustion products.

As described mathematically in the sections and equations below, the two-zone thermodynamic model is employed to compute the states of the global mixture, the end-gas, and the post-flame zones from the input pressure time history data. Here, the term 'global' refers to the combined end-gas and post-flame system. The analysis is performed using three major sequential steps. First, a standard heat release analysis procedure (e.g. see [11, 12]) is performed to obtain the time history of the global combustion heat release and the heat transfer scaling factor for energy closure. Then, the advanced combustion analysis is used to estimate the time of auto-ignition, multi-mode burn rates and heat transfer. Lastly, the two-zone model is used to compute the thermodynamic states of the system using the estimated combustion and heat transfer parameters.

The numerical approach calculates the global and end-gas state and composition using species and energy conservation equations. The post-flame zone state and composition are then determined algebraically by balancing mass and energy. The high-fidelity computational SACI 
model by Martz [21] employed a similar method, which was the basis for this work. In general, the variables directly related to the end-gas and post-flame zones are denoted by the subscripts $u$ and $b$, respectively. This notation is historically consistent, but the subscripts do not necessarily signify unburned and burned quantities, since the current two-zone model allows for autoignition chemistry in the end-gas. The global rate of change for the $k^{\text {th }}$ species is given by the individual contributions from end-gas auto-ignition $\left(\dot{m}_{A I}^{k}\right)$, flame propagation $\left(\dot{m}_{F L}^{k}\right)$, and evolving chemical equilibrium in the post-flame zone $\left(\dot{m}_{b}^{k}\right)$ :

$\frac{d m^{k}}{d t}=\dot{m}_{b}^{k}+\dot{m}_{F L}^{k}+\dot{m}_{A I}^{k}$

The rate of change of the $k^{t h}$ species in the end-gas is computed in a similar fashion, considering only the contributions from auto-ignition $\left(\dot{m}_{u, A I}^{k}\right)$ and flame propagation $\left(\dot{m}_{u, F L}^{k}\right)$ :

$\frac{d m_{u}^{k}}{d t}=\dot{m}_{u, F L}^{k}+\dot{m}_{u, A I}^{k}$

The evolution of post-flame zone composition is computed based on the equilibrium state for the current pressure and post-flame zone temperature. Flame propagation is modeled as a combustion process where the end-gas species $\left(Y_{u}^{k}\right)$ are converted into equilibrium products at constant pressure and enthalpy at the burning rate for flame propagation $\left(\dot{x}_{b, F L}\right) . \dot{x}_{b, F L}$ is calculated using a novel method developed for this work which is described in Section 2.4.

The updated end-gas composition due to auto-ignition $\left(\left.Y_{u}^{k}\right|^{A I}\right)$ is obtained from the local end-gas reaction progress $x_{b, E G}$, where the unburned reactants $\left(Y_{u, r e a c}^{k}\right)$, taken at some time before any combustion occurs, are converted to combustion products $\left(Y_{u, p r o d}^{k}\right)$ assuming either complete combustion or equilibrium:

$\left.Y_{u}^{k}\right|^{A I}=\left(1-x_{b, E G}\right) Y_{u, \text { reac }}^{k}+x_{b, E G} Y_{u, p r o d}^{k}$

$x_{b, E G}$ is defined as the instantaneous fraction of the total fuel energy released locally in the endgas by auto-ignition, accounting for combustion efficiency. It is assumed to be equivalent to the mass fraction burned for the purpose of estimating composition and properties. The method for estimating $x_{b, E G}$ is presented in Section 2.4. 
The total internal energy rate equation for the closed system is computed based on the First Law of Thermodynamics, accounting for boundary work $(P d V)$ and heat transfer to the walls $\left(\dot{Q}^{H T}\right)$ :

$\frac{d U}{d t}=-P \frac{d V}{d t}-\dot{Q}^{H T}$

For the end-gas, an open-cycle version of the First Law of Thermodynamics using the total enthalpy $H_{u}$ is used:

$\frac{d H_{u}}{d t}=V_{u} \frac{d P}{d t}-\dot{Q}_{u}^{H T}+\sum \dot{m}_{u, F L}^{k} h_{u}^{k}$

In Eqn. (5), $V_{u}$ is the volume of the end-gas zone, $\dot{Q}_{u}^{H T}$ is the volume-scaled zonal heat transfer, and $\sum \dot{m}_{u, F L}^{k} h_{u}^{k}$ is the enthalpy out-flow due to flame consumption. Section 2.5 describes the calculation of the global heat transfer rate from Newton's Cooling Law with convection coefficients based on well-known empirical correlations. Knowledge of the global and end-gas state and composition is then used to algebraically solve for the post-flame conditions.

The two-zone model also provides the means to compute laminar flame speeds that are then used to interpret and further understand the experimental data. The recent correlations developed by Middleton et al. [22] were used to calculate the laminar flame speed during the flame propagation portion of the cycle. The correlations were developed for iso-octane for a wide range of conditions, including temperatures and dilution levels relevant to SACI operating conditions.

\subsection{Global Combustion Heat Release}

A basic First Law of Thermodynamics approach was used to estimate the global combustion heat release rate from the cylinder pressure data [23]. The gross chemical heat release rate from combustion $\left(d Q_{c h}^{H R} / d t\right)$ can be expressed as:

$\frac{d Q_{c h}^{H R}}{d t}=m c_{v} \frac{d T}{d t}+P \frac{d V}{d t}+\dot{Q}^{H T}$

where $m, c_{v}$, and $T$ are the estimated mass, specific heat at constant volume, and mean gas temperature, respectively. $P$ is the measured cylinder pressure and $V$ is the total cylinder volume, computed from a crank-slider relationship and the engine geometry. $\dot{Q}^{H T}$ is the global heat transfer rate, calculated using empirical correlations for the convection coefficient (see Section 
2.5). The first two terms on the right hand side of Equation (6) are the net apparent heat release rate $\left(d Q_{n e t}^{H R} / d t\right)$, which includes the change in sensible energy and piston work. The mean gas temperature required for the heat release analysis and estimating the thermodynamic properties is computed from the Ideal Gas Law equation of state. As seen in the form of Equation (6), errors in the experimental pressure data, pre-conditioning of the experimental data, and estimates of mass and heat transfer can directly influence $Q_{c h}^{H R}$.

The overall energy balance is enforced using a heat transfer scaling factor, $\alpha_{H T}$, computed as the ratio of gross chemical heat release at exhaust valve opening (EVO) and expected fuel energy released $\left(\eta_{\text {comb }} m_{f u e l} Q_{L H V}\right)[24]$ :

$\alpha_{H T}=\frac{\eta_{c o m b} m_{f u e l} Q_{L H V}-Q_{n e t}^{H R}(E V O)}{Q^{H T}(E V O)}$

The first term in the numerator includes the combustion efficiency $\eta_{c o m b}$, fuel mass $m_{f u e l}$ and lower heating value of the fuel $Q_{L H V}$. The second term in the numerator and the term in the denominator are the cumulative net heat release and heat loss, respectively, at EVO. The $\alpha_{H T}$ factor is used as a multiplier to the estimated heat transfer loss when calculating the final $Q_{c h}^{H R}$ value, and ensures that the gross heat release is equivalent to the sum of the heat loss and net heat release. Enforcing energy closure using $\alpha_{H T}$ combines errors from other sources, such as incorrect values for reference pressure, compression ratio, or residual mass, to name a few, into heat transfer. This could adversely affect the shape of the heat release curve, i.e. lead to nonphysical heat transfer behavior. Therefore, as done in this work, a thorough evaluation of the sensitivity of the results to the errors in the experimental data should be carried out to understand the most influential sources of error.

The burn fraction $x_{b}$ is the fraction of heat release relative to the total chemical heat release $Q_{c h}^{H R}$ between the start (SOC) and end of combustion (EOC). SOC and EOC are assumed to be the minimum and maximum points of $Q_{c h}^{H R}$. The rate of heat release ( $\left.R o H R\right)$ is obtained by numerical differentiation of the $Q_{c h}^{H R}$ with respect to crank-angle. Similarly, the burn rate $\dot{x}_{b}$ is the numerical derivative of the time history of the burn fraction. The estimate for energy-based burn fraction is used interchangeably as a mass fraction in the mass-based calculations. This is a necessary assumption to estimate the composition and thermodynamic properties given the lack 
of information on the mass-based burning rates when performing experimental heat release analysis. The associated error is expected to be minimal compared to other assumptions related to heat transfer and in-cylinder mass. This applies to all burn fractions and rates described in this work.

The combustion efficiency $\eta_{c o m b}$ is computed from exhaust emissions measurements using the standard approach presented by Stivender [25], and corrected using an expression proposed by Chang [26] to account for the re-inducted fuel from dilution by exhaust gas recirculation (EGR).

The mean gas composition is assumed to be a mixture of unburned and burned gases, weighted by the burned mass fraction $x_{b}$ :

$Y^{k}=\left(1-x_{b}\right) \cdot Y_{u}^{k}+x_{b} \cdot Y_{b}^{k}$

where $Y^{k}$ is the mass fraction of the $k^{t h}$ species. The unburned composition $Y_{u}^{k}$ is modeled as a mixture of fresh reactants $Y_{\text {reac }}^{k}$, determined from the given equivalence ratio and the EGR composition, weighted by the trapped EGR fraction (defined in a later section):

$Y_{u}^{k}=(1-E G R) \cdot Y_{\text {reac }}^{k}+E G R \cdot Y_{E G R}^{k}$

The burned species $Y_{b}^{k}$ are obtained assuming chemical equilibrium at the instantaneous temperature and pressure ( $Y_{\text {equil }}^{k}$ ), which allows high-temperature dissociation of combustion products above a specified temperature threshold. Below the temperature threshold the burned species are assumed to be complete combustion products $\left(Y_{\text {prod }}^{k}\right)$.

To calculate gas properties throughout the cycle, the heat release analysis is performed iteratively. The first iteration uses an estimate based on the properties of the fresh charge at intake valve closing (IVC) and the residual gas properties. Once the burn fraction profile is obtained, Equation (8) is used to obtain the composition and gas properties as a function of crank-angle. The maximum temperature, maximum gross heat release and $\alpha_{H T}$ are used as convergence variables.

\subsection{Method to Determine the Time of Auto-Ignition}

Auto-ignition is a principal feature of combustion modes such as HCCI and SACI, and the effects of operating conditions and control strategies on auto-ignition timing need to be 
understood. The chemically controlled nature of auto-ignition makes it difficult to identify with certainty when the gas initially begins reacting (e.g. $0 \%$ burn fraction). Still, it is possible to estimate the timing of the main auto-ignition event $\left(\theta_{I G N}\right)$ by analysis of the heat release profiles derived from the experimental in-cylinder pressure data. For HCCI combustion, it is straightforward to identify the time of auto-ignition, since combustion proceeds solely due to auto-ignition, but SACI combustion requires a more rigorous approach to capture the transition between slow spark-ignited deflagration and fast auto-ignition heat release. Persson et al. [6] identified two distinct regions in the heat release rate data from SACI experiments using the maximum of the second derivative of the RoHR or RoHR". Physically, the first maximum in $R o H R^{\prime \prime}$ represents the transition between combustion dominated by slow flame propagation to combustion dominated by rapid auto-ignition. In the current work, the use of $R o H R^{\prime \prime}$ consistently predicted later auto-ignition compared to the expected timing based on visual inspection of the experimental heat release rate data. Therefore, the normalized rate of heat release, denoted as $\overline{R o H R}$, was used in the current work, together with $R o H R^{\prime \prime}$. Specifically, the curvature of $\overline{R o H R}$, defined as $\kappa_{\overline{R o H R}}$, was employed. $\kappa_{\overline{R o H R}}$ was calculated using the definition for the curvature of a line in two-dimensional Cartesian coordinates, with RoHR as the ordinate and crank-angle as the abscissa:

$\kappa_{\overline{R o H R}}=\frac{\overline{R o H R}^{\prime \prime}}{\left(1+\overline{R o H R}^{\prime 2}\right)^{3 / 2}}$

In Equation (10), $\overline{R o H R}^{\prime}$ and $\overline{R o H R}^{\prime \prime}$ are the first and second derivatives of the normalized heat release rate. For this method, the RoHR data are smoothed to minimize the noise in the higher derivatives, particularly when performing cycle-to-cycle analysis.

Figure 2 shows the $\mathrm{RoHR}, \mathrm{RoH} \mathrm{R}^{\prime \prime}$ and $\kappa_{\overline{R o H R}}$ calculated from typical SACI experimental engine data. (The experimental conditions and engine details are described later in this paper). The average time of the first maxima in the $R o H R^{\prime \prime}$ and the time of the first maxima in $\kappa_{\overline{R o H R}}$, marked as $\theta_{I G N}$ in the figure, was found to be a robust and accurate method for detecting the timing of bulk auto-ignition. Because auto-ignition is a process driven by local chemical kinetics, it is difficult to formulate a clear definition for the actual onset and to determine a quantitative performance metric; therefore, visual inspection of the data was used for this assessment. This was considered sufficient because the objective of this method is to obtain trend-wise estimates 
of auto-ignition timing from global experimental and simulation data (e.g. pressure and heat release).

Currently, the method for estimating the time of auto-ignition is limited to cases where the effects of auto-ignition can be clearly detected, i.e. where the pressure and heat release data show noticeable inflexion points as a result of rapid auto-igniting combustion. The method is expected to break down at marginal auto-igniting conditions; however, these cases are generally of less interest in advanced combustion research. Employing additional methods such as an ignition delay integral could potentially be used to improve robustness, but an ignition delay integral would likely require a more complex iterative process due to the dependence on end-gas temperature.

\subsection{Determining the SACI Flame and Auto-Ignition Burn Fractions}

Accurately estimating the fraction of combustion heat release that occurs due to flame propagation compared to auto-ignition is critical to accurately interpreting experimental data of advanced combustion modes like SACI. To first order accuracy, all of the combustion heat release prior to the time of auto-ignition, $\theta_{I G N}$, could be attributed to flame propagation, and all combustion heat release after auto-ignition could be attributed to end-gas auto-ignition chemistry. However, this assumption of distinct combustion modes would significantly overestimate the auto-ignition burn rate. To overcome this limitation, a semi-empirical method to capture the combustion mode transition was developed in this work. Insights from simulation studies by Martz and co-workers [27] and observations from extensive analysis of HCCI and SACI experiments were used to develop the semi-empirical method.

The estimate for auto-ignition timing $\left(\theta_{I G N}\right)$ is the critical input parameter, designated as the time when the combustion mode is transitioned in the analysis from flame propagation to autoignition. The method then calculates the relative burn fractions (i.e. the fractions of heat release by flame or auto-ignition at any particular time during the cycle relative to the total heat release of the cycle) and the burn rates due to flame and auto-ignition $\left(x_{b, F L}, \dot{x}_{b, F L}, x_{b, A I}, \dot{x}_{b, A I}\right)$, where:

$x_{b, F L}+x_{b, A I}=x_{b}$ 
In addition, the local end-gas reaction progress $\left(x_{b, E G}\right)$ is computed using Equation (12) based on the estimated auto-ignition burn fraction, $x_{b, A I}$, and combustion efficiency, $\eta_{c o m b, A I}$ (see Equation (13)):

$x_{b, E G}=\eta_{c o m b, A I} \frac{x_{b, A I}}{\max \left(x_{b, A I}\right)}$

To obtain physically meaningful results, continuous burn fraction time histories for flame propagation and end-gas auto-ignition are desired. This was achieved by employing a series of assumptions regarding the burn rate behavior and implemented using simple mathematical relationships. First, an exponential function was used to fit the auto-ignition burn rate between $1 \%$ burn fraction and $\theta_{I G N}$. The duration, $\Delta \theta_{1 \%-I G N}$, was set as 10 crank-angle degrees $\left({ }^{\circ} \mathrm{CA}\right)$. The burn fraction at $\theta_{I G N}$ was also specified as $x_{b, E G}=5 \%$, which is equivalent to stating that $5 \%$ of the total combustion heat release attributed to auto-ignition has occurred by the time of $\theta_{I G N}$, or mathematically that $x_{b, A I, I G N} / \eta_{c o m b, A I}=5 \%$. To enforce rapid quenching of the flame after the main auto-ignition event, an exponential decay on $\dot{x}_{b, F L}$ was also imposed. The time constant, $\tau_{0.1 \%}$, was obtained by assuming a duration of $10^{\circ}$ from the onset of auto-ignition to where $x_{b, F L}$ reaches $0.1 \%$.

These assumptions are based on extensive analysis of experimental data and high fidelity simulation results of HCCI and SACI combustion. They represent an approximate average of the observed values and remained constant for all operating conditions. The approach is described pictorially in Figure 3. The method is iterative, where an initial guess is made for $\eta_{c o m b, A I}$ to perform the initial calculations, and the steps are repeated until $\eta_{c o m b, A I}$ converges to $0.001 \%$ of the previous value. Errors introduced by this approach are expected to increase for conditions with noticeably slower transition chemistry or where the maximum flame propagation burn fraction is on the order of $5 \%$.

The auto-ignition combustion efficiency $\left(\eta_{c o m b, A I}\right)$ is computed by algebraic manipulation of Equation (11) at the end of combustion, where by definition $x_{b}$ is equal to the global combustion efficiency, $\eta_{c o m b}$. Then, assuming the burn fraction by flame reaches a maximum at the onset of auto-ignition, $x_{b, F L}=x_{b, F L, I G N}$, and $x_{b, A I}=\left(1-x_{b, F L, I G N}\right) \cdot \eta_{c o m b, A I}$. The latter expression assumes that the only source of combustion inefficiency comes from auto-ignition, and implies 
that the post-flame zone equilibrium composition will eventually reach complete combustion products. Finally, solving for $\eta_{c o m b, A I}$ gives:

$\eta_{c o m b, A I}=\frac{\left(\eta_{c o m b}-x_{b, F L, I G N}\right)}{\left(1-x_{b, F L, I G N}\right)}$

Because the burn fraction can be at most equal to the combustion efficiency, this expression is numerically stable at the limit, where $\eta_{c o m b, A I} \rightarrow 0$ for $x_{b, F L, I G N} \rightarrow \eta_{c o m b}$ and $\eta_{c o m b}<1$.

Sensitivity analysis for the parameters $\Delta \theta_{1 \%-I G N}, x_{b, A I, I G N} / \eta_{c o m b, A I}$ and $\tau_{0.1 \%}$ was conducted. Each parameter was varied from the baseline values to low and high values. Overall, the results were the most sensitive to $x_{b, A I, I G N} / \eta_{c o m b, A I}$, and the most noticeable effects were on $x_{b, F L, I G N}$ and $x_{b, F L, \max }$, which changed by $\pm 3 \%$ on an absolute scale from the baseline values of $20 \%$ and $26 \%$, respectively. Relatively smaller variations were observed for other key quantities

\subsection{Heat Transfer Model for Multi-Mode Combustion}

Heat transfer is computed based on correlations found in the literature derived from the Reynolds Analogy. These provide a global convective heat transfer coefficient $h^{H T}\left(\mathrm{~W} / \mathrm{m}^{2}-\mathrm{K}\right)$ that is, in general, a function of temperature $T$, pressure $P$ and mean piston speed $\overline{S_{p}}$, as well as a length scale given either by the volume $V$, the bore $B$ or the instantaneous chamber height $L$. The most common heat transfer models are listed in Table 1, Equations (17) to (20), using a shared set of units for length $[\mathrm{m}]$, pressure $[\mathrm{kPa}]$, temperature $[\mathrm{K}]$ and velocity $[\mathrm{m} / \mathrm{s}]$.

The Woschni-based correlations (Woschni, Chang, and Woschni-ACE in Table 1) have a characteristic gas velocity term $w\left(w, w_{\text {mod }}, w_{A C E}\right)$ calculated from the expression:

$w=C_{1} \overline{S_{p}}+C_{2} V_{d}\left(\frac{T_{r}}{P_{r} V_{r}}\right)\left(P-P_{m o t}\right)$

The characteristic velocity is proportional to the mean piston speed, $\overline{S_{P}}(\mathrm{~m} / \mathrm{s})$, and a 'pressure velocity' given by the difference between the firing and motoring cylinder pressure $\left(P_{\text {mot }}\right)$ scaled by the displaced volume, $V_{d}\left(\mathrm{~m}^{3}\right)$, and the temperature $\left(T_{r}\right)$, pressure $\left(P_{r}\right)$ and volume $\left(V_{r}\right)$ at some reference condition (e.g. IVC). The 'pressure velocity' or 'flame enhancement' term is assumed to account for increases in heat transfer due to flame-induced turbulence. As suggested 
by Woschni [28], the constants used in the heat transfer correlation are $C_{1}=2.28$ and $C_{2}=$ $3.24 \times 10^{-3}$ for the closed cycle.

Given the extensive use of the Woschni model in heat release analysis and engine simulations, some researchers have opted to modify Woschni's expression when new phenomena are not captured by the original correlation. Such is the case with the Chang [24] model, where a 1/6 reduction factor on the flame enhancement term and a different temperature coefficient were proposed based on experimental heat flux studies in an HCCI engine. Other modified correlations have also been developed for HCCI combustion [24, 31-33].

These and other global heat transfer correlations have been the subject of numerous studies investigating their applicability to different combustion modes [24, 31-41]. Multi-mode SACI combustion, however, has yet to be the subject of an in-depth heat transfer investigation. To address this shortcoming, a simple hybrid model designated as the Woschni-ACE is proposed here (Equation (21) in Table 1). The model combines the standard Woschni correlation with the reduced pressure velocity term suggested by Chang [24]. During the flame propagation phase or pure SI combustion, the model behaves exactly like the standard Woschni model. After the estimated occurrence of auto-ignition, the reduced pressure velocity term is imposed. The performance of this model is compared with the other heat transfer correlations in a later section.

The global heat transfer rate is assumed to be the sum of individual contributions from the head, piston and liner, and is computed based on the mean gas temperature. The head area and the

piston area are specified for a given engine, and the liner area is computed using the crank-slider equations. The wall temperatures of these three regions $\left(T_{\text {head }}, T_{\text {pist }}\right.$ and $\left.T_{\text {linr }}\right)$ are prescribed as constant values, whereas the mean gas temperature is calculated on a crank-angle basis during the heat release analysis.

\subsection{Determining the Trapped In-Cylinder Mass}

Accurate estimation of the total mass in the cylinder is crucial when calculating quantities such as mean gas temperature, which affects gas properties and the overall energy balance. The total mass includes the fuel, air and re-circulated exhaust gas (EGR):

$m_{\text {tot }}=m_{\text {fuel }}+m_{\text {air }}+m_{e-E G R}+m_{i-E G R}$ 
where $m_{f u e l}$ is the injected fuel mass, $m_{\text {air }}$ is the inducted air mass, $m_{e-E G R}$ is the mass of EGR introduced with the intake flow (external) and $m_{i-E G R}$ is the internally trapped EGR or residual gas fraction $(\mathrm{RGF})$ mass.

Several independent measurements methods are used for the mass flow of fuel and air into the cylinder. In addition to direct metering and exhaust-gas lambda $(\lambda)$ sensors, the air-fuel ratio is also computed using emissions data from the standard Brettschneider formula [42] and atomic balance expressions for carbon and oxygen. The external EGR fraction, which can be significant in advanced combustion engines, is computed from $\mathrm{CO}_{2}$ measurements in the intake and exhaust, with the resulting EGR mass obtained based on the total incoming flow.

Obtaining realistic estimates for the residual mass is critical for advanced combustion engines employing valve strategies to trap large amounts of hot internal EGR, such as Negative Valve Overlap (NVO). Various residual mass estimation methods of relatively low complexity are implemented in ACE-HRA. For NVO operation, the Fitzgerald Method [43, 44] generally provides the best results. For more details on the models and implementation, as well as an indepth assessment of the various methods, the reader is referred to [44]. These methods calculate the residual mass at exhaust valve closing (EVC), from which the RGF (internal) and total EGR fraction (internal + external) can be determined. Other methods of increasing complexity and cost, such as direct measurement techniques [45, 46] or coupled engine models using onedimensional gas dynamics [47] are also available, but are beyond the scope of this work.

EGR is approximated as a mixture of fresh reactants $\left(Y_{\text {reac }}^{k}\right)$ and complete combustion products $\left(Y_{\text {prod }}^{k}\right)$ computed for the given fuel and measured equivalence ratio, weighted by the combustion efficiency $\left(\eta_{\text {comb }}\right)$ :

$Y_{E G R}^{k}=\left(1-\eta_{c o m b}\right) \cdot Y_{\text {reac }}^{k}+\eta_{c o m b} \cdot Y_{\text {prod }}^{k}$

The EGR composition is necessary to obtain the gas properties used in the residual mass estimation methods. Although this assumption does not take into account the actual exhaust species measured by an emissions bench, the discrepancy in the calculated properties is expected to be minor. The thermo-physical gas properties were determined using standard reference data as described in Error! Reference source not found.. 


\section{Validation of ACE-HRA with Higher Fidelity Model Predictions}

The new thermodynamic models and advanced combustion analysis methods in ACE-HRA were validated by comparison with data from a series of closed-cycle high-fidelity SACI engine simulations conducted using the KIVA-3V computational fluid dynamics (CFD) code. In the KIVA model, auto-ignition chemistry was modeled using a coupled CFD/Multi-Zone (MZ) approach [48]. The 215 species skeletal reaction mechanism for iso-octane of Tham et al. [49] was used with the KIVA model to compute the chemical kinetics and gas properties. Turbulent flame propagation was simulated in the KIVA model using a Coherent Flamelet Model (CFM) [21, 50, 51], developed based on direct numerical simulations (DNS). The auto-ignition and flame propagation models used in the high-fidelity simulation were separately validated. The KIVA SACI engine simulations were validated using optical and metal engine data. A full description of the model can be found in $[21,51]$.

The KIVA results provide a data set with detailed predictions of heat release rates, in-cylinder temperatures, auto-ignition timing, flame speeds and other key parameters not resolved or measured in engine experiments. Uncertainties related to cylinder pressure referencing, mass and initial composition estimates, and combustion efficiency are eliminated, allowing the validation focus to remain on the subset of models and assumptions used to extract combustion information from the experimental pressure data.

The engine configuration for the KIVA simulations is shown in Table 2. For each case, the KIVA pressure time histories (like those shown in Figure 4) were used as input data for the ACE-HRA tool. The operating conditions are summarized in Table 3. The in-cylinder pressure time histories of the SACI cases are shown in Figure 4. These conditions were selected for validation of the ACE-HRA tool because they are representative of practical SACI operation, and conditions where fuel efficiency improvements are critical.

The SACI validation study achieved a similar overall combustion phasing (CA50) and maximum pressure throughout the various cases by trading-off initial temperature for spark advance. Earlier spark timing and lower IVC temperature results in pressure data that appear more SI-like (i.e. more gradual and earlier pressure rise) than HCCI-like, whereas later spark timing and higher temperatures result in more HCCI-like behavior (i.e. more rapid and later pressure rise). The initial pressure, equivalence ratio $(\Phi)$ and $E G R$ were held nearly constant. Here, the 
equivalence ratio is defined as the dimensionless molar ratio of the fuel to fresh air in the charge compared to the molar stoichiometric of fuel to air ratio. The equivalence ratio does not consider the $\mathrm{O}_{2}$ in the EGR gases, which includes contributions from both external and internal exhaust gases. Unless otherwise noted, the Woschni-ACE correlation was used to model heat transfer. The general soundness of the thermodynamic model and heat release analysis was assessed using motoring (non-firing, non-reacting) and adiabatic simulations, and was found to be satisfactory.

\subsection{Auto-Ignition and SACI Burn Fractions}

The subsequent step in the analysis is the estimation of auto-ignition timing from the global combustion profile. Good qualitative agreement between the estimated and expected locations was found in all of the validation cases upon visual inspection, e.g. see Figure 5. Even for SACI cases with later phasing and moderate fractions of initial flame propagation, the auto-ignition event was well identified.

Based on the auto-ignition timing, the burn fractions by flame and auto-ignition are then estimated. A comparison between the KIVA and the ACE-HRA predictions from Case 2 of the validation study is presented in Figure 5. Overall, the plots show very good agreement between the two sets of results. The KIVA results show the flame heat release rate quickly becomes negligible, and this characteristic appears well-captured by the ACE-HRA method.

The global combustion phasing $(\mathrm{CA} \%)$ and end-gas reaction progress fractions $(\mathrm{EG} \%)$ from the KIVA simulations and the ACE-HRA model are compared in Figure 6. The estimated autoignition timing (CA-IGN) is also shown. Excellent trend-wise and absolute agreement is found between the KIVA and ACE-HRA results, with a maximum error less than one-third of a crankangle degree at EG90. This agreement is essential to build confidence that the estimates of the global, end-gas and post-flame zone states from the thermodynamic model are representative of the in-cylinder conditions. The results also show the fundamental characteristics of multi-mode SACI combustion. The delay between the global CA10 and CA-IGN decreases from Case \#1 to Case \#3 as the mixture temperature increases and spark is retarded, even though CA-IGN remains relatively constant. This indicates that the relative amount of slow flame propagation is decreasing and the cases are becoming more HCCI-like. Within the end-gas, the more straightforward relationship between CA-IGN and the local EG combustion phasing is indicative of the consistent and rapid burn nature of auto-ignition. 


\subsection{Thermodynamic Two-Zone Model}

The thermodynamic two-zone model for advanced multi-mode combustion computes the global, end-gas and post-flame states given the measured pressure time history, the estimated initial conditions, and the combustion profiles for flame propagation and auto-ignited combustion. Figure 7 compares the resulting temperature estimates from ACE-HRA with the KIVA simulations for Case 2 of the validation study. Negligible errors in mean or global temperature were found during both compression and expansion; however, the maximum error of the global temperature during combustion increased to $2 \%$. The trends were similar throughout the validation cases, and the error in maximum temperature in every case was less than $0.5 \%$.

The end-gas temperature also shows very good agreement. Differences, such as those found during the early to mid-stages of auto-ignition, are almost certainly related to the assumptions made in the ACE-HRA model regarding the prescribed initial burn and the combustion mode transition. The KIVA model is also spatially resolved, where the ACE-HRA model is not. So temperature gradients could be another source of discrepancy between the models.

The difference in the post-flame zone temperature is also small, particularly before and during combustion, where it remains under $1 \%$. During expansion, however, there is a noticeable offset in the post-flame temperature between ACE-HRA and KIVA. This is likely due to differences in treatment of the post-flame gas between the two models. Given the time in the cycle when it occurs, the difference is not expected to be a concern.

The end-gas temperature at spark timing $\left(T_{E G, S P K}\right)$ and auto-ignition timing $\left(T_{E G, I G N}\right)$, as well as the maximum values $\left(T_{E G, M A X}\right)$ are compared in Figure 8, along with the calculated laminar flame speed $\left(S_{L}\right)$ at the times of spark and auto-ignition. All three temperatures show excellent absolute and trend-wise agreement. The good agreement for $T_{E G, I G N}$ for all the validation cases indicates the approximation for the early heat release due to pre-ignition chemistry, as well as the ignition timing estimate, are representative of the physics described by the higher-fidelity KIVA model. The small differences between the ACE-HRA and KIVA results may be due to multidimensional effects not captured in the zero-dimensional ACE-HRA model, or differences in pre-ignition chemistry. 
The KIVA simulation results for $\left(S_{L}\right)$ were determined by averaging the flame speed values of the computational cells in the end-gas. There was negligible difference between the KIVA and ACE-HRA results for $S_{L, S P K}$ for all the validation cases, which is in large part due to the almost identical end-gas temperatures of the two models. The relatively low temperature at the time of spark also means that no significant ignition chemistry would have occurred prior to this point. On the other hand, differences in the end-gas temperature and composition at the time of autoignition lead to more noticeable differences in $S_{L, I G N}$. Still, the trends are captured relatively well.

\subsection{Heat Transfer Modeling}

The effects of using the modified Woschni-ACE model are compared in Figure 9 with results determined using the other heat transfer correlations listed in Table 1. The figure includes predictions for cumulative heat loss, the energy balance, and the heat transfer energy closure factor, $\alpha_{H T}$. Significant differences in the heat loss predictions are observed, especially after auto-ignition. Of the models considered, the Woschni-ACE correlation (5) proposed in the current work resulted in the lowest energy balance error of $0.26 \%$ and a heat transfer closure factor closest to unity at 0.97 . For comparison, the standard Woschni correlation (1) produced the largest energy balance error of $5.4 \%$ and the lowest heat transfer closure factor of 0.57 . The cases evaluated are dominated by auto-ignited combustion. Only the Woschni-ACE and Chang correlations were developed to account for the reduced heat transfer enhancement from turbulence as the flame decays beyond the auto-ignition event. The results demonstrate the hybrid Woschni-ACE correlation provides a reasonable approximation to the heat transfer behavior of multi-mode SACI operation.

The effects of heat transfer with $\left(\alpha_{H T} O N\right)$ and without $\left(\alpha_{H T} O F F\right)$ forced closure of the energy balance are shown in Figure 10. CA02, CA10, CA50 and CA90 are the crank-angles at 2\%, 10\%, $50 \%$ and $90 \%$ burn, respectively. Comparing the results without forced energy closure (blue squares), CA50 is minimally affected by the choice of heat transfer model. This robustness is one of the reasons CA50 is a good metric for combustion phasing. However, the early portion of the heat release curve is more sensitive, as suggested by the results for CA02 and CA10. Application

of $\alpha_{H T}$ to force energy closure (red diamonds) can help improve the agreement of the combustion phasing results compared with KIVA (black circles) for these earlier burn criteria. 
This is most significant for the Hohenberg model (3) where heat transfer is the highest during this initial combustion period. Otherwise, these cases show only minor differences between the analysis with and without forced energy closure. This can be attributed to the fact that the majority of the information on combustion is contained in the pressure data used as input, so changes in the analysis assumptions have relatively small effects on the estimated burn characteristics.

\section{Sensitivity Analysis to Key Input Parameters}

Sensitivity analysis of key parameters was performed to assess the impact from uncertainties inherent to the experimental data, models, inputs, and assumptions used in ACE-HRA. Some of the parameters considered included the type of ensemble analysis, engine geometry, data preconditioning, and the parameters of the thermodynamic and combustion models. A representative experimental operating condition for SACI combustion was used for the analysis. The engine speed was 2000 RPM, with a fueling rate of $19 \mathrm{mg} /$ cycle. The average intake

pressure and temperature were 1 bar and $321 \mathrm{~K}$, respectively. The exhaust pressure was set slightly above the intake pressure to 1.05 bar. The desired SACI combustion phasing was achieved with $128^{\circ}$ of NVO, an external EGR flow of $20 \%$ and spark advance at $34^{\circ}$ BTC. A similar exercise was performed for an HCCI case with similar results.

Each input parameter for the sensitivity analysis was perturbed to a high and low value from the baseline setting, and the effect on numerous output parameters was determined, including net IMEP, maximum global rate of heat release $\left(R o H R_{\max }\right)$, and ringing intensity (R.I.). The complete list of input and output parameters considered in the sensitivity analysis is provided in Error! Reference source not found. The sensitivity of each output parameter is reported in absolute or relative terms.

Comparing cycle-by-cycle analysis against the more common ensemble average analysis showed the largest differences in rate-based quantities, such as the RoHR and R.I., on the order of $25 \%$. This is expected due to the inherent filtering that occurs when averaging the pressure data. The various pre-conditioning and geometry parameters also showed notable impact on combustion rates and phasing, burn duration, mass estimation and temperature calculations. Overall, mass 
estimation errors affected the analysis to the greatest extent, with most results changing by $10 \%$ or more, whereas heat transfer parameters showed minimal effects.

\section{Demonstration of ACE-HRA for Experimental Analysis of a Multi-Mode Combustion Engine}

After validating the ACE-HRA with the KIVA simulation, the capabilities of ACE-HRA were demonstrated by application to a recent experimental study by Olesky et al. [52]. In the SACI study, the authors investigated the effects of spark timing and unburned temperature on combustion phasing and burn rate. The engine was operated unthrottled at $2000 \mathrm{rev} / \mathrm{min}$ and a fixed fueling rate of $19 \mathrm{mg} / \mathrm{cycle}$, where net IMEP was approximately 6 bar. The composition was kept relatively constant at a stoichiometric equivalence ratio and a total in-cylinder EGR content of $40 \%$. The experimental pressure data were preconditioned using the methods described in Error! Reference source not found.. NVO was used to regulate the initial temperature through hot internal residuals, and cooled external EGR was adjusted to retain the same overall dilution rate. Spark advance was simultaneously adjusted to achieve a CA50 around $8^{\circ}$ after top dead center (ATC).

Figure 11 shows ensemble-averaged pressure time histories and estimated heat release rates of 200 consecutive cycles for three cases. The cases represent the midpoint and the two extremes of the five published experimental cases. The case with the least amount of NVO and in turn the coolest charge has the most spark advance, resulting in more SI-like combustion with a larger portion of slow flame propagation heat release. The case with the most NVO and consequently the hottest charge also has the most retarded spark, and shows a much faster combustion event approaching typical HCCI behavior.

The results of applying the advanced combustion analysis methods in ACE-HRA to the experimental data are shown in Figure 12. The ACE-HRA data show the combustion phasing and peak burn rate trends as a function of burn fraction by flame at the estimated time of auto-

ignition $\left(x_{b, F L, I G N}\right)$. For the experiments in this study, the burn fraction by flame propagation increases from $\sim 10 \%$ to $\sim 30 \%$ as the charge cools and spark is advanced. CA50 combustion phasing remains relatively constant throughout the study, whereas the burn rates decrease 
significantly as the burn fraction by flame increases and combustion changes from HCCI-like to SI-like behavior. Cases with a larger portion of flame propagation show larger cyclic variability as indicated by the error bars. This can be attributed to the larger degree of stochastic behavior added to the combustion event as the importance of turbulence increases with higher levels of flame propagation. As noted in the experimental study, the results show the potential of sparkassist to vary combustion phasing and burn rate independently.

Additional insights are obtained by examining the combustion behavior locally of the end-gas (EG) in terms of auto-ignition timing (CA-IGN), combustion phasing (EG50) and EG burn rate. The results show that both global and end-gas peak burn rates decrease with increasing $x_{b, F L, I G N}$. For the global burn rate, this is expected since more of the charge is consumed by slow flame propagation. However, this is not the case locally in the end-gas. Ideally, at a fixed engine speed, the burn rate in the auto-ignited region should only be affected by ignition phasing, composition, temperature and pressure as dictated by chemical kinetics. In this study, the changes in ignition timing, combustion phasing, ignition temperature and composition as the flame fraction increases are relatively small. Furthermore, the pressure at ignition increases with increasing flame burn fraction, which tends to increase the burn rate when operating outside the negative temperature coefficient (NTC) region, as expected for these cases. These observations imply that the EG burn rate should either increase, or at least not decrease in such a monotonic fashion as observed in Figure 12. Therefore, it can be inferred that additional phenomena are involved.

Thermal or mixture stratification could potentially play a role, although in this case the effect would be directionally inconsistent because more NVO is expected to increase stratification and decrease burn rate. Recent high fidelity simulation results of SACI combustion, such as those used in the validation section, have shown that flame propagation can also affect the thermal and compositional gradients controlling auto-ignition burn rates [51]. Hence, it is reasonable to conclude from these results that as the flame consumes more of the end-gas, the temperature gradients within the unburned charge increase and, in turn, the cascading auto-ignition process slows. It is also possible that with more of the end-gas mass pushed near the wall, the heat transfer can increase, thus cooling the reacting end-gas mixture and slowing the auto-ignition event. This decreasing trend in the end-gas burn rate is critical for in-depth understanding of SACI combustion and a key feature that computational models need to incorporate. 
The results in Figure 12 also show an interesting trend in cycle-to-cycle variability. Even though the coefficient of variation (COV) of $I M E P_{n e t}$ is on the order of 1-3\%, the peak pressure varies much more significantly, with the COV ranging from $8-12 \%$. This is also apparent in the combustion phasing and burn rate results, where the error bars shown are $25 \%$ of a standard deviation. The COV generally increases with increasing $x_{b, F L, I G N}$, which can be attributed to more substantial stochastic behavior inherent to turbulent combustion, coupled with enhanced cyclic feedback due to NVO and the high sensitivity of auto-ignited combustion to the thermodynamic conditions in the cylinder. This is a feature studied in detail by Sen et al. [53] and immediately suggests that care must be taken when retrieving and interpreting combustion results from SACI experiments, as the ensemble-averaged data are likely to be very different from the true cycle-by-cycle data and could potentially conceal interesting and important phenomena. It also demonstrates that more in-depth investigation into the cycle-by-cycle behavior of SACI combustion is of great importance for fully understanding and developing applications of this technology.

\section{Summary and Conclusions}

This paper described new methods for advanced combustion analysis that integrate previous analytical methods for global heat release, gas properties and mass estimation with new algorithms to describe the unique features of advanced combustion strategies like SACI. The new models and methods developed included a two-zone thermodynamic model to estimate the states of the end-gas and post-flame regions, programmatic methods for estimating auto-ignition timing and multi-mode burn fractions, and a modified heat transfer model to account for the simultaneous presence of auto-ignition and flame propagation during SACI combustion.

The new thermodynamic models and advanced combustion analysis methods in ACE-HRA were validated by comparison with a series of closed-cycle high fidelity KIVA-3V engine simulations for SACI combustion. The validation results showed good agreement, in particular for the twozone temperatures, auto-ignition timing and SACI multi-mode burn fractions.

Sensitivity analysis revealed uncertainties in estimates of mass affected the ACE-HRA predictions to the greatest extent, with most output data changing by $10 \%$ or more. Differences 
in rate-based quantities, such as the RoHR and R.I., on the order of $25 \%$ were also observed when comparing cycle-by-cycle analysis with the more common ensemble-average analysis.

The enhanced analytical capabilities in ACE-HRA were demonstrated by application to a recent experimental study for SACI combustion. The advanced multi-mode combustion analysis methods were used to infer the effects of flame propagation on in-cylinder gradients and cycleto-cycle variability, and provided quantitative results for associated change in the end-gas burn rate. These trends are critical for in-depth understanding of SACI combustion and identifying key features of SACI combustion. In summary, the ACE-HRA tool developed in this work provides more in-depth understanding of advanced combustion experiments and can be used as a powerful tool for interpreting experimental trends.

\section{Acknowledgments}

The authors acknowledge the generous financial support of the National GEM Consortium, Oak Ridge National Laboratory (ORNL) Fuels, Engines and Emissions Research Center (FEERC), and the U.S. Department of Energy (DOE) via the University Consortium on Efficient and Clean High-Pressure, Lean Burn (HPLB) Engines.

\section{Abbreviations}

$\begin{array}{ll}\text { A/BTC } & \text { After/before top dead center } \\ \text { ACE } & \text { Advanced combustion engine } \\ \text { AI } & \text { Auto-ignition } \\ \text { BC } & \text { Bottom dead center } \\ \text { CA } & \text { Crank-angle } \\ \text { CFD } & \text { Computational fluid dynamics } \\ \text { CFM } & \text { Coherent flamelet model } \\ \text { COV } & \text { Coefficient of variability } \\ \text { CR } & \text { Compression ratio }\end{array}$




\begin{tabular}{|c|c|}
\hline EG & End-gas \\
\hline EGR & Exhaust gas recirculation \\
\hline EOC & End of combustion \\
\hline EVC & Exhaust valve closing \\
\hline EVO & Exhaust valve opening \\
\hline FFVA & Fully-flexible valve actuation \\
\hline HCCI & $\begin{array}{l}\text { Homogeneous charge compression } \\
\text { ignition }\end{array}$ \\
\hline HR & Heat release \\
\hline HT & Heat transfer \\
\hline IMEP & Indicated mean effective pressure \\
\hline IMPR & Intake manifold pressure referencing \\
\hline IVC & Intake valve closing \\
\hline IVO & Intake valve opening \\
\hline MMC & Multi-mode combustion \\
\hline MZ & Multi-zone \\
\hline NTC & Negative temperature coefficient \\
\hline NVO & Negative valve overlap \\
\hline PIPR & Polytropic index pressure referencing \\
\hline R.I. & Ringing intensity \\
\hline RGF & Residual gas fraction \\
\hline RoHR & Rate of heat release \\
\hline SA & Spark advance \\
\hline SACI & Spark-assisted compression ignition \\
\hline SI & Spark ignition \\
\hline SOC & Start of combustion \\
\hline
\end{tabular}




\section{Definitions}

\begin{tabular}{|c|c|}
\hline$\alpha_{H T}$ & Heat transfer energy closure factor \\
\hline$\gamma$ & Specific heat ratio \\
\hline$\eta_{\text {comb }}$ & Combustion efficiency \\
\hline $\boldsymbol{\theta}$ & Crank-angle \\
\hline $\boldsymbol{\kappa}$ & Curvature \\
\hline$\Phi$ & Fuel/air equivalence ratio \\
\hline$c_{v}$ & Specific heat at constant volume \\
\hline $\boldsymbol{h}$ & Specific enthalpy \\
\hline$h^{H T}$ & Convection heat transfer coefficient \\
\hline$m$ & Mass \\
\hline$m^{k}$ & Mass of species $k$ \\
\hline $\boldsymbol{t}$ & Time \\
\hline$x_{b}$ & Burn fraction \\
\hline $\boldsymbol{A}$ & Combustion chamber surface area \\
\hline $\boldsymbol{B}$ & Cylinder bore \\
\hline $\mathbf{C A}(\mathbf{X})$ & Crank-angle at X\% burn (e.g. CA50) \\
\hline $\mathbf{E G}(\mathbf{X})$ & $\begin{array}{l}\text { Crank-angle at X\% EG burn (e.g. } \\
\text { EG50) }\end{array}$ \\
\hline $\boldsymbol{H}$ & Total enthalpy \\
\hline$L$ & Characteristic heat transfer length \\
\hline $\boldsymbol{P}$ & Pressure \\
\hline$Q^{H R}$ & Heat release \\
\hline$Q^{H T}$ & Heat transfer \\
\hline
\end{tabular}




$\begin{array}{ll}\boldsymbol{Q}_{\boldsymbol{L H V}} & \text { Lower heating value } \\ \boldsymbol{R} & \text { Gas constant } \\ \boldsymbol{S}_{\boldsymbol{L}} & \text { Laminar flame speed } \\ \overline{\boldsymbol{S}_{\boldsymbol{p}}} & \text { Mean piston speed } \\ \boldsymbol{T} & \text { Temperature } \\ \boldsymbol{U} & \text { Total internal energy } \\ \boldsymbol{V} & \text { Combustion chamber volume } \\ \boldsymbol{Y}^{\boldsymbol{k}} & \text { Mass fraction of species } k\end{array}$

\section{Subscripts/Superscripts}

$\begin{array}{ll}\text { air } & \text { Air-related quantity } \\ \boldsymbol{b} & \text { Post-flame zone } \\ \boldsymbol{c y l} & \text { In-cylinder quantity } \\ \boldsymbol{d} & \text { Displacement } \\ \boldsymbol{e}-\boldsymbol{E G} \boldsymbol{R} & \text { External EGR } \\ \boldsymbol{e x h} & \text { Exhaust-based quantity } \\ \boldsymbol{f u e l} & \text { Fuel-related quantity } \\ \boldsymbol{i}-\boldsymbol{E G} \boldsymbol{R} & \text { Internal EGR } \\ \boldsymbol{p e a k} / \boldsymbol{m a x} & \text { Peak or maximum value } \\ \boldsymbol{p r o d} & \text { Combustion products } \\ \boldsymbol{r} & \text { Reference value } \\ \boldsymbol{r e a c} & \text { Unburned reactants } \\ \boldsymbol{t} \text { tot } & \text { Total-based quantity } \\ \boldsymbol{u} & \text { End-gas zone } \\ \boldsymbol{A I} & \text { End-gas auto-ignition quantity }\end{array}$




$\begin{array}{ll}\boldsymbol{E G} & \text { End-gas quantity } \\ \boldsymbol{F L} & \text { Flame-based quantity } \\ \boldsymbol{I G N} & \text { Value at auto-ignition timing } \\ \boldsymbol{S P K} & \text { Value at spark timing }\end{array}$

\section{References}

1. Onishi, S., Jo, S. H., Shoda, K., Do Jo, P., and Kato, S., "Active Thermo-Atmosphere Combustion (ATAC) - A New Combustion Process for Internal Combustion Engines," SAE International, 1979, doi: $10.4271 / 790501$.

2. Najt, P. M., and Foster, D. E., "Compression-Ignited Homogeneous Charge Combustion," 1983.

3. Thring, R. H., "Homogeneous-Charge Compression-Ignition (HCCI) Engines," SAE International, 1989, doi: $10.4271 / 892068$.

4. Willand, J., Nieberding, R.-G., Vent, G., and Enderle, C., "The Knocking Syndrome - Its Cure and Its Potential," 1998.

5. Weinrotter, M., Wintner, E., Iskra, K., Neger, T., Olofsson, J., Seyfried, H., Aldén, M., Lackner, M., Winter, F., Vressner, A., Hultqvist, A., and Johansson, B., "Optical Diagnostics of Laser-Induced and Spark Plug-Assisted HCCI Combustion,” Copyright (C) 2005 SAE International, 2005, doi:10.4271/2005-01-0129.

6. Persson, H., Hultqvist, A., and Johansson, B., "Investigation of the Early Flame Development in Spark Assisted HCCI Combustion Using High Speed Chemiluminescence Imaging," SAE Technical Paper 2007-01-0212, 2007, doi: $10.4271 / 2007-01-0212$.

7. Zigler, B. T., Walton, S. M., Karwat, D. M., Assanis, D., Woolridge, M. S., and Woolridge, S. T., "A Multi-Axis Imaging Study of Spark-Assisted Homogeneous Charge Compression Ignition Phenomena in a Single-Cylinder Research Engine," ASME Internal Combustion Engine Division 2007 Fall Technical Conference, ICEF2007-1701, 2007.

8. Manofsky, L., Vavra, J., Assanis, D., and Babajimopoulos, A., "Bridging the Gap between HCCI and SI: Spark-Assisted Compression Ignition,” SAE Technical Paper 2011-011179, 2011, doi:10.4271/2011-01-1179.

9. Szybist, J. P., Nafziger, E., and Weall, A., "Load Expansion of Stoichiometric HCCI Using Spark Assist and Hydraulic Valve Actuation," 2010.

10. Lavoie, G. A., Ortiz-Soto, E., Babajimopoulos, A., Martz, J. B., and Assanis, D. N., "Thermodynamic sweet spot for high-efficiency, dilute, boosted gasoline engines," International Journal of Engine Research 14(3):260-278, 2013, doi: $10.1177 / 1468087412455372$.

11. Gatowski, J. A., Balles, E. N., Chun, K. M., Nelson, F. E., Ekchian, J. A., and Heywood, J. B., "Heat release analysis of engine pressure data," SAE Technical Paper 841359, 1984, doi: $10.4271 / 841359$.

12. Brunt, M. F. J., Rai, H., and Emtage, A. L., "The Calculation of Heat Release Energy from Engine Cylinder Pressure Data," SAE Technical Paper 981052, 1998, doi: $10.4271 / 981052$. 
13. Guezennec, Y. G., and Hamama, W., "Two-Zone Heat Release Analysis of Combustion Data and Calibration of Heat Transfer Correlation in an I. C. Engine," SAE Technical Paper 1999-01-0218, 1999, doi:10.4271/1999-01-0218.

14. Catania, A. E., Misul, D., Mittica, A., and Spessa, E., "Unsteady Convection Model for Heat Release Analysis of IC Engine Pressure Data," SAE Technical Paper 2000-01-1265, 2000, doi:10.4271/2000-01-1265.

15. Catania, A. E., Misul, D., Mittica, A., and Spessa, E., "A Refined Two-Zone Heat Release Model for Combustion Analysis in SI Engines," JSME International Journal 46(1), 2003.

16. Kulzer, A., Lejsek, D., Kiefer, A., and Hettinger, A., "Pressure Trace Analysis Methods to Analyze Combustion Features and Cyclic Variability of Different Gasoline Combustion Concepts," SAE Technical Paper 2009-01-0501, 2009, doi:10.4271/2009-01-0501.

17. Fathi, M., Saray, R. K., and Checkel, M. D., "Detailed approach for apparent heat release analysis in HCCI engines," Fuel 89(9):2323-2330, 2010, doi:10.1016/j.fuel.2010.04.030.

18. Baratta, M., and Misul, D., "Development and assessment of a new methodology for end of combustion detection and its application to cycle resolved heat release analysis in IC engines," Applied Energy 98:174-189, 2012, doi:10.1016/j.apenergy.2012.03.020.

19. Tabaczynski, R. J., Ferguson, C. R., and Radhakrishnan, K., "A Turbulent Entrainment Model for Spark-Ignition Engine Combustion," 1977.

20. Heywood, J. B., Higgins, J. M., Watts, P. A., and Tabaczynski, R. J., "Development and Use of a Cycle Simulation to Predict SI Engine Efficiency and NOx Emissions," 1979.

21. Martz, J. B., "Simulation and Model Development for Auto-Ignition and Reaction Front Propagation in Low-Temperature High-Pressure Lean-Burn Engines," Ph. D. Thesis, University of Michigan, 2010.

22. Middleton, R. J., Martz, J. B., Lavoie, G. A., Babajimopoulos, A., and Assanis, D. N., “A computational study and correlation of premixed isooctane air laminar reaction fronts diluted with EGR," Combustion and Flame 159(10):3146-3157, 2012, doi:10.1016/j.combustflame.2012.04.014.

23. Heywood, J. B., Internal Combustion Engine Fundamentals. McGraw-Hill, Inc., 1988.

24. Chang, J., Guralp, O., Filipi, Z., Assanis, D., Kuo, T.-W., Najt, P., and Rask, R., "New Heat Transfer Correlation for an HCCI Engine Derived from Measurements of Instantaneous Surface Heat Flux," SAE Technical Paper 2004-01-2996, 2004, doi: 10.4271/2004-01-2996.

25. Stivender, D. L., "Development of a Fuel-Based Mass Emission Measurement Procedure," SAE Technical Paper 710604, 1971, doi:10.4271/710604.

26. Chang, K., "Modeling and Analysis of an HCCI Engine During Thermal Transients Using a Thermodynamic Cycle Simulation With a Coupled Wall Thermal Network," Ph. D. Thesis, University of Michigan, 2010.

27. Martz, J. B., Lavoie, G. A., Im, H. G., Middleton, R. J., Babajimopoulos, A., and Assanis, D. N., "The propagation of a laminar reaction front during end-gas auto-ignition," Combustion and Flame 159(6):2077-2086, 2012, doi:10.1016/j.combustflame.2012.01.011.

28. Woschni, G., "A Universally Applicable Equation for the Instantaneous Heat Transfer Coefficient in the Internal Combustion Engine," SAE Technical Paper 670931, 1967, doi:10.4271/670931.

29. Hohenberg, G. F., "Advanced Approaches for Heat Transfer Calculations," SAE Technical Paper 790825, 1979, doi: $10.4271 / 790825$. 
30. Eichelberg, G., "Some New Investigations on Old Combustion Engine Problems," Engineering 148:463-466 and 547-550, 1939.

31. Tsurushima, T., Kunishima, E., Asaumi, Y., Aoyagi, Y., and Enomoto, Y., "The Effect of Knock on Heat Loss in Homogeneous Charge Compression Ignition Engines," SAE Technical Paper 2002-01-0108, 2002, doi:10.4271/2002-01-0108.

32. Hensel, S., Sarikoc, F., Schumann, F., Kubach, H., Velji, A., and Spicher, U., "A New Model to Describe the Heat Transfer in HCCI Gasoline Engines," SAE Technical Paper 2009-01-0129, 2009, doi:10.4271/2009-01-0129.

33. Komninos, N. P., and Kosmadakis, G. M., "Heat transfer in HCCI multi-zone modeling: Validation of a new wall heat flux correlation under motoring conditions," Applied Energy 88(5):1635-1648, 2011, doi:10.1016/j.apenergy.2010.11.039.

34. Suzuki, T., Oguri, Y., and Yoshida, M., "Heat Transfer in the Internal Combustion Engine," SAE Technical Paper 2000-01-0300, 2000, doi:10.4271/2000-01-0300.

35. Hajireza, S., and Sunden, B., "Prediction of Heat Transfer to the Walls for Autoignition Related Situations in SI Engines," SAE Technical Paper 2000-01-1084, 2000, doi:10.4271/2000-01-1084.

36. Grandin, B., and Assanis, D. N., "The Effect of Knock on Heat Transfer in SI Engines," SAE Technical Paper 2002-01-0238, 2002, doi:10.4271/2002-01-0238.

37. Sharief, A., and Chandrashekar, T. K., "Study on Heat Transfer Correlation in IC Engines," SAE Technical Paper 2008-01-1816, 2008, doi:10.4271/2008-01-1816.

38. Junior, R. T. M., and Belchior, C. R. P., "Analysis of Different Correlations for Heat Transfer to the Cylinder Wall in Spark-Ignition Engines with a Generalized Computational Algorithm," SAE Technical Paper 2008-36-0187, 2008, doi:10.4271/200836-0187.

39. Hensel, S., Sarikoc, F., Schumann, F., Kubach, H., and Spicher, U., "Investigation on the Heat Transfer in HCCI Gasoline Engines," SAE Technical Paper 2009-01-1804, 2009, doi:10.4271/2009-01-1804.

40. Caton, J. A., "Comparisons of Global Heat Transfer Correlations for Conventional and High Efficiency Reciprocating Engines," presented at the ASME 2011 Internal Combustion Engine Division Fall Technical Conference, ICEF2011-60017, 2011.

41. Lounici, M. S., Loubar, K., Balistrou, M., and Tazerout, M., "Investigation on heat transfer evaluation for a more efficient two-zone combustion model in the case of natural gas SI engines," Applied Thermal Engineering 31(2-3):319-328, 2011, doi:10.1016/j.applthermaleng.2010.09.012.

42. Brettschneider, J., "Berechnung des luftverhaeltnisses lambda von luft-kraftstoff gemischen und des einflusses von messfehlern auf lambda," Robert Bosch GMB, 1979.

43. Fitzgerald, R. P., Steeper, R. R., Snyder, J. A., Hanson, R. K., and Hessel, R. P., "Determination of Cycle Temperatures and Residual Gas Fraction for HCCI NVO Operation," SAE Technical Paper 2010-01-0343, 2010, doi:10.4271/2010-01-0343.

44. Ortiz-Soto, E. A., Vavra, J., and Babajimopoulos, A., "Assessment of Residual Mass Estimation Methods for Cylinder Pressure Heat Release Analysis of HCCI Engines With Negative Valve Overlap," Journal of Engineering for Gas Turbines and Power 134(8), 2012, doi:10.1115/1.4006701.

45. Rothamer, D. A., Snyder, J. A., Hanson, R. K., Steeper, R. R., and Fitzgerald, R. P., "Simultaneous imaging of exhaust gas residuals and temperature during HCCI combustion," Proceedings of the Combustion Institute 32(2):2869-2876, 2009, 
doi:10.1016/j.proci.2008.07.018.

46. Prucka, R. G., Filipi, Z. S., and Assanis, D. N., "An Evaluation of Residual Gas Fraction Measurement Techniques in a High Degree of Freedom Spark Ignition Engine," SAE Technical Paper 2008-01-0094, 2008, doi:10.4271/2008-01-0094.

47. GTI, “GT-SUITE Engine Performance Application Manual,” Gamma Technologies, 2010.

48. Babajimopoulos, A., Assanis, D. N., Flowers, D. L., Aceves, S. M., and Hessel, R. P., “A fully coupled computational fluid dynamics and multi-zone model with detailed chemical kinetics for the simulation of premixed charge compression ignition engines,"

International Journal of Engine Research 6(5):497-512, 2006, doi:10.1243/146808705X30503.

49. Tham, Y. F., Bisetti, F., and Chen, J.-Y., "Development of a Highly Reduced Mechanism for Iso-Octane HCCI Combustion With Targeted Search Algorithm," Journal of Engineering for Gas Turbines and Power 130(4):042804-042807, 2008, doi:10.1115/1.2900729.

50. Vanzieleghem, B. P., "Combustion Modeling for Gasoline Direct Injection Engines Using KIVA-3V," Ph. D. Thesis, University of Michigan, 2004.

51. Middleton, R. J., "Simulation of Spark Assisted Compression Ignition Combustion Under EGR Dilute Engine Operating Conditions," Ph. D. Thesis, University of Michigan, 2014.

52. Olesky, L. M., Martz, J. B., Lavoie, G. A., Vavra, J., Assanis, D. N., and Babajimopoulos, A., "The effects of spark timing, unburned gas temperature, and negative valve overlap on the rates of stoichiometric spark assisted compression ignition combustion," Applied Energy 105:407-417, 2013, doi:10.1016/j.apenergy.2013.01.038.

53. Sen, A. K., Litak, G., Edwards, K. D., Finney, C. E. A., Daw, C. S., and Wagner, R. M., "Characteristics of cyclic heat release variability in the transition from spark ignition to HCCI in a gasoline engine," Applied Energy 88(5):1649-1655, 2011, doi:10.1016/j.apenergy.2010.11.040.

54. "NIST-JANAF Thermochemical Tables," "NIST-JANAF Thermochemical Tables." http://kinetics.nist.gov/janaf/.

55. Burcat, A., "Prof. Burcat's Thermodynamic Data." http://garfield.chem.elte.hu/Burcat/burcat.html.

56. Lanzafame, R., and Messina, M., "ICE Gross Heat Release Strongly Influenced by Specific Heat Ratio Values," International Journal of Automotive Technology 4(3):135133, 2003.

57. Egnell, R. " "Combustion Diagnostics by Means of Multizone Heat Release Analysis and NO Calculation," SAE Technical Paper 981424, 1998, doi:10.4271/981424.

58. Klein, M., and Eriksson, L., "A specific heat ratio model for single-zone heat release models," SAE Technical paper 2004-01-1464, 2004, doi:10.4271/2004-01-1464.

59. Ceviz, M. A., and Kaymaz, İ., "Temperature and air-fuel ratio dependent specific heat ratio functions for lean burned and unburned mixture," Energy Conversion and Management 46(15-16):2387-2404, 2005, doi:10.1016/j.enconman.2004.12.009.

60. Kee, R. J., Rupley, F. M., Meeks, E., and Miller, J. A., "Chemkin-III: A Fortran Chemical Kinetics Package for the Analysis of Gas-Phase and Plasma Kinetics," Sandia National Laboratories, 1996.

61. Depcik, C., Jacobs, T., Hagena, J., and Assanis, D., "Instructional use of a single-zone, premixed charge, spark-ignition engine heat release simulation," International Journal of Mechanical Engineering Education 35(1):1-31, 2007. 
62. Olikara, C., and Borman, G. L., "A Computer Program for Calculating Properties of Equilibrium Combustion Products with Some Applications to I.C. Engines," SAE Technical Paper 750468, 1975, doi:10.4271/750468.

63. Goldsborough, S. S., "On the Rate of Heat Release for High-Boost, Low-Temperature Combustion Schemes: Accounting for Compressibility Effects," Combustion Science and Technology 181(5):729-755, 2009, doi:10.1080/00102200902857757.

64. Randolph, A. L., "Methods of Processing Cylinder-Pressure Transducer Signals to Maximize Data Accuracy,” SAE Technical Paper 900170, 1990, doi:10.4271/900170.

65. Brunt, M. F. J., and Pond, C. R., "Evaluation of Techniques for Absolute Cylinder Pressure Correction," SAE Technical Paper 970036, 1997, doi:10.4271/970036. 


\section{Tables}

Table 1. Global engine heat transfer correlations available in ACE-HRA.

\begin{tabular}{|c|l|}
\hline Woschni [28] & $h^{H T}=3.26 \cdot B^{-0.2} \cdot P^{0.8} \cdot T^{-0.53} \cdot w^{0.8}$ \\
\hline Chang [24] & $h^{H T}=3.4 \cdot 3.26 \cdot L^{-0.2} \cdot P^{0.8} \cdot T^{-0.73} \cdot w_{\text {mod }}^{0.8}$ \\
\hline Hohenberg [29] & $h^{H T}=3.26 \cdot V^{-0.06} \cdot P^{0.8} \cdot T^{-0.4} \cdot\left(\overline{S_{p}}+1.4\right)^{0.8}$ \\
\hline Eichelberg [30] & $h^{H T}=0.24 \cdot P^{1 / 2} \cdot T^{1 / 2} \cdot \bar{S}_{p}^{1 / 3}$ \\
\hline Woschni-ACE & $h^{H T}=3.26 \cdot B^{-0.2} \cdot P^{0.8} \cdot T^{-0.55} \cdot w_{A C E}^{0.8}$ \\
\hline
\end{tabular}

Table 2. Engine geometry used in high-fidelity KIVA simulations.

\begin{tabular}{|c|c|}
\hline Compression Ratio & 12.42 \\
\hline Bore $\times$ Stroke $(\mathrm{mm})$ & $86.0 \times 94.3$ \\
\hline Displaced Volume $\left(\mathrm{cm}^{3}\right)$ & 547.8 \\
\hline Connecting Rod Length $(\mathrm{mm})$ & 152.2 \\
\hline
\end{tabular}


Table 3. Nominal operating conditions for KIVA simulations of SACI combustion.

\begin{tabular}{|c|c|c|c|}
\hline Case Number & $\mathbf{1}$ & $\mathbf{2}$ & $\mathbf{3}$ \\
\hline Engine Speed (rev/min) & 1991 & 1999 & 1996 \\
\hline Initial Pressure (bar) & 1.25 & 1.29 & 1.28 \\
\hline Initial Temperature (K) & 482 & 505 & 513 \\
\hline Fueling Rate (mg/cyc) & 18.5 & 18.4 & 18.3 \\
\hline Equivalence Ratio, $\Phi$ & 0.99 & 1.00 & 1.00 \\
\hline Trapped EGR (\%) & 40 & 40 & 40 \\
\hline Spark Advance $\left({ }^{\circ} \mathrm{CA} \mathrm{BTC}\right)$ & 44 & 34 & 25 \\
\hline IVC $\left({ }^{\circ} \mathrm{CA}\right.$ ATC) & -139 & -139 & -139 \\
\hline EVO $\left({ }^{\circ} \mathrm{CA}\right.$ ATC) & +139 & +139 & +139 \\
\hline Wall Temperature (K) & 400 & 400 & 400 \\
\hline Gross IMEP (bar) & 7.1 & 6.5 & 6.2 \\
\hline
\end{tabular}




\section{Figures}

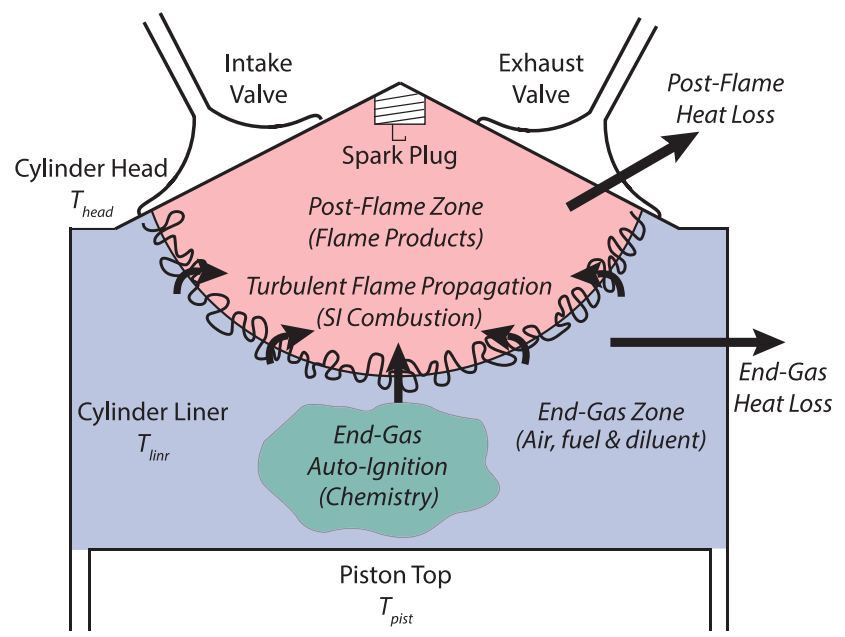

Figure 1. Schematic of the conceptual two-zone thermodynamic model used to represent the different modes of combustion, including SI, HCCI and SACI.

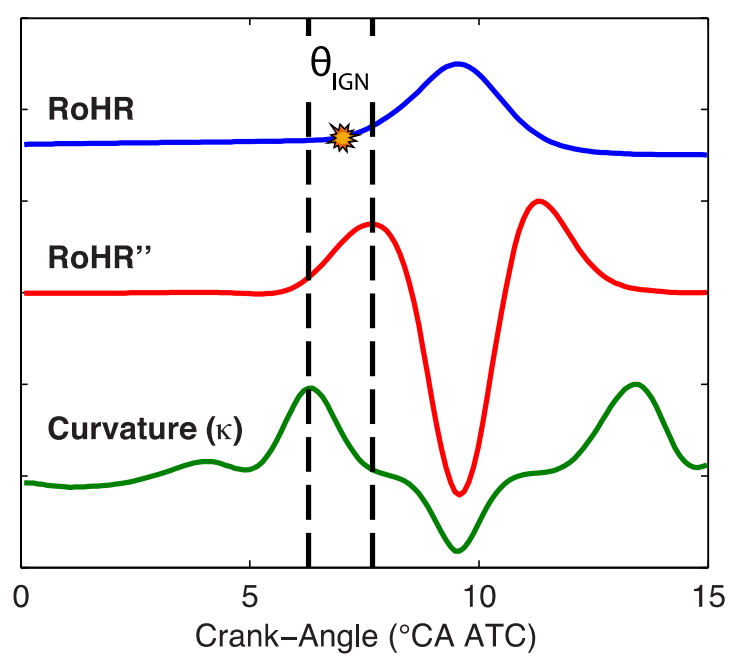

Figure 2. Non-dimensional representation of the rate of heat release (RoHR), the second derivative of the RoHR (RoHR') and the curvature parameter $(\kappa)$ used for estimating the main auto-ignition event during HCCI and SACI engine operation. The time of auto-ignition $\left(\theta_{\mathrm{IGN}}\right)$ is assumed to be at the arithmetic average of the time of the first maxima in the RoHR" and the time of the first maxima in $\kappa$. 


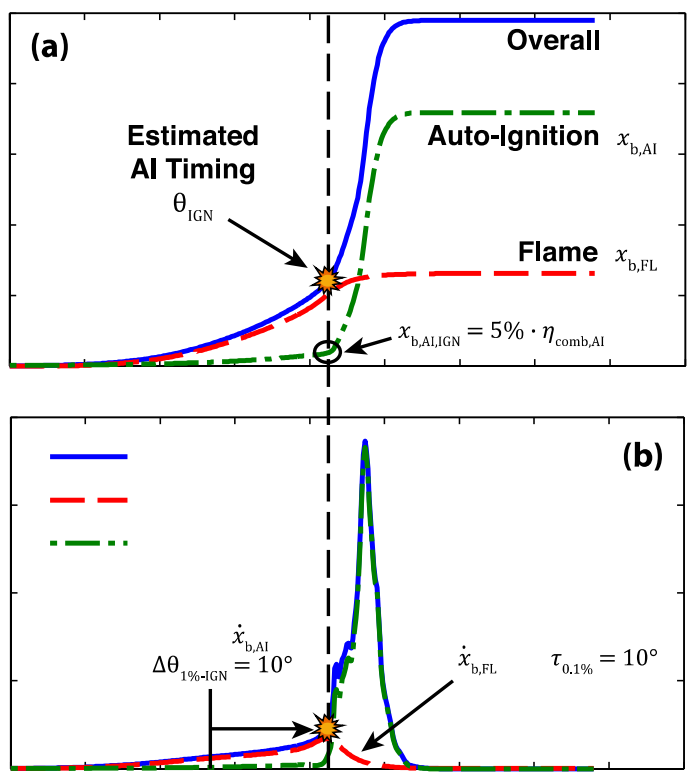

Figure 3. Pictorial description of the semi-empirical method developed in the current work for estimating the flame and auto-ignition burn fractions in multi-mode SACI combustion. The plots for (a) burn fractions and (b) burn rates are annotated with the respective combustion modes, as well as the key assumptions necessary to obtain a continuous burn fraction profile. 


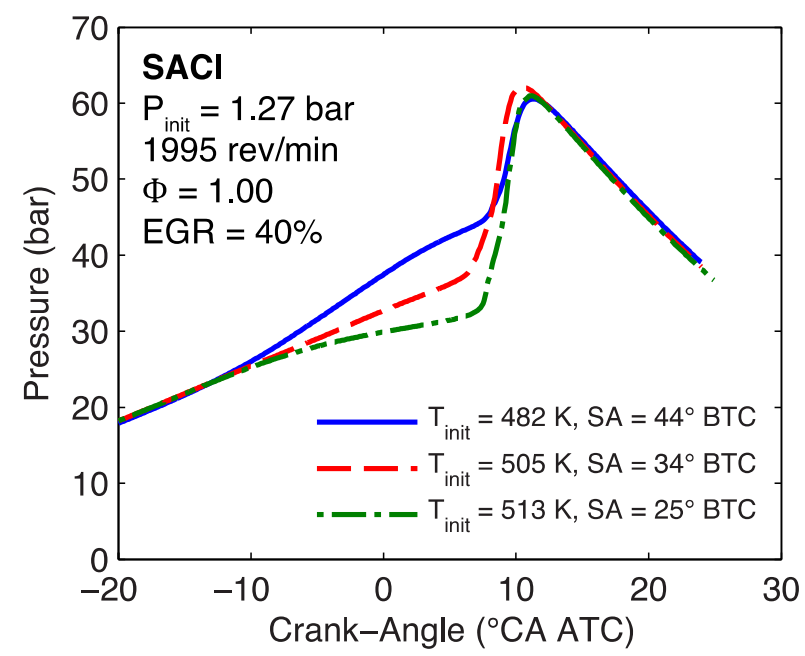

Figure 4. KIVA model cylinder pressure predictions for SACI simulations. These results were used for validation of the new ACE-HRA methods. The SACI cases are based on a study which used initial temperature $\left(\mathrm{T}_{\text {init }}\right)$ and spark advance (SA) to control combustion phasing and burn rate at fixed initial pressure $\left(\mathrm{P}_{\text {init }}\right)$, engine speed, and composition ( $\Phi$, EGR).
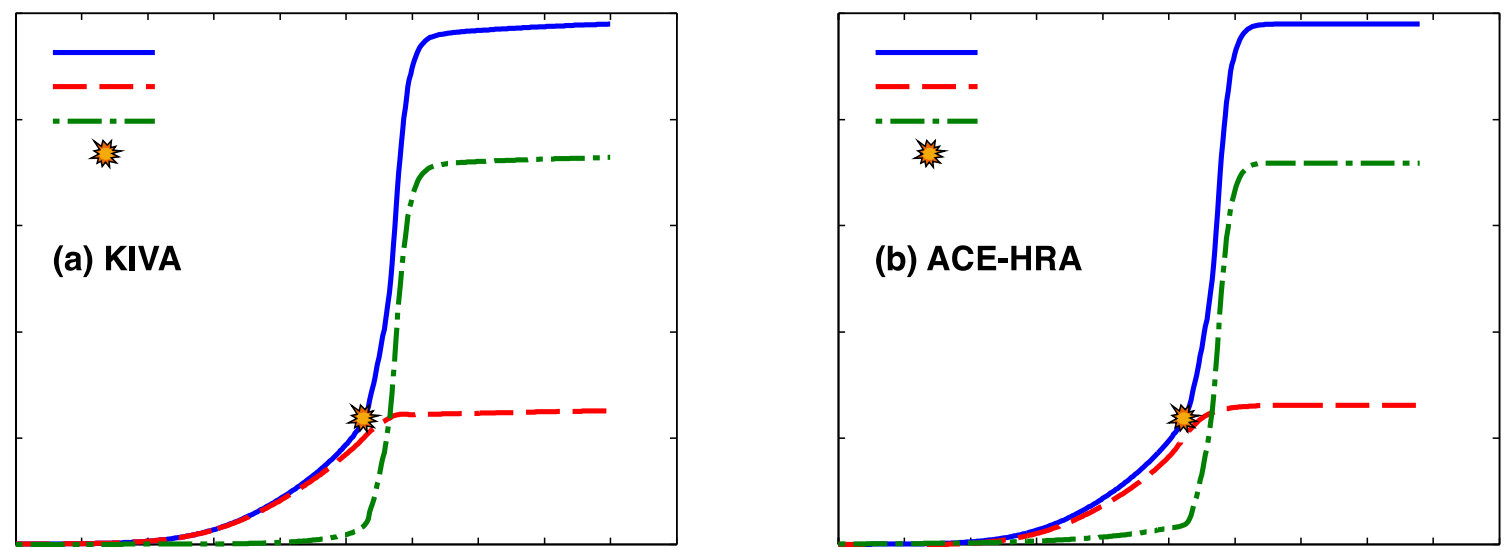

Figure 5. Comparison (a) KIVA model predictions and (b) ACE-HRA advanced combustion analysis estimate of flame and auto-ignition burn fractions for Case 2 of the SACI validation study. Good agreement is observed in the general shape and behavior of the flame and auto-ignition burn time histories. 
(a) Global Combustion

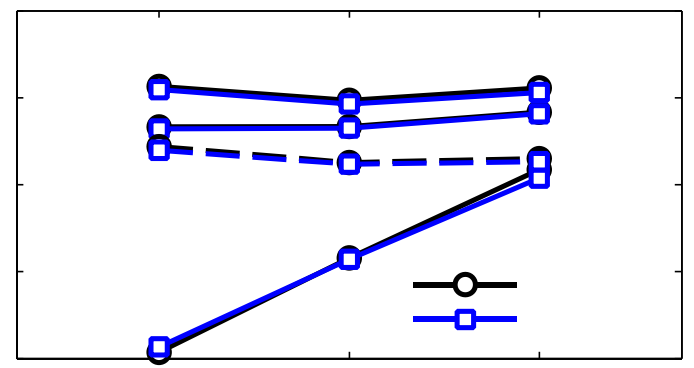

(b) End-Gas Auto-Ignition

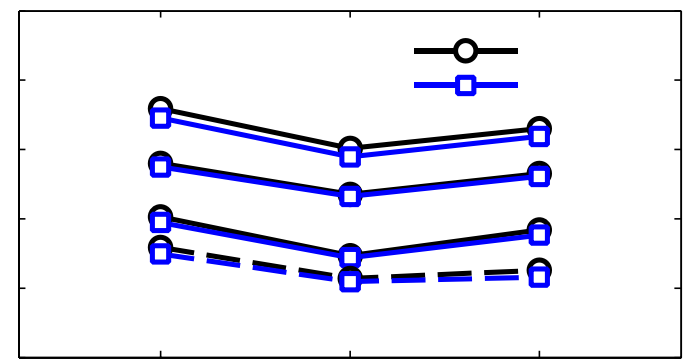

Figure 6. KIVA and ACE-HRA (a) global combustion phasing and (b) end-gas reaction progress from SACI validation study. The latter results are obtained by normalizing the relative auto-ignition burn fraction curves and extracting the timing at the given burn fractions. The estimated auto-ignition timing (CA-IGN) is also shown.
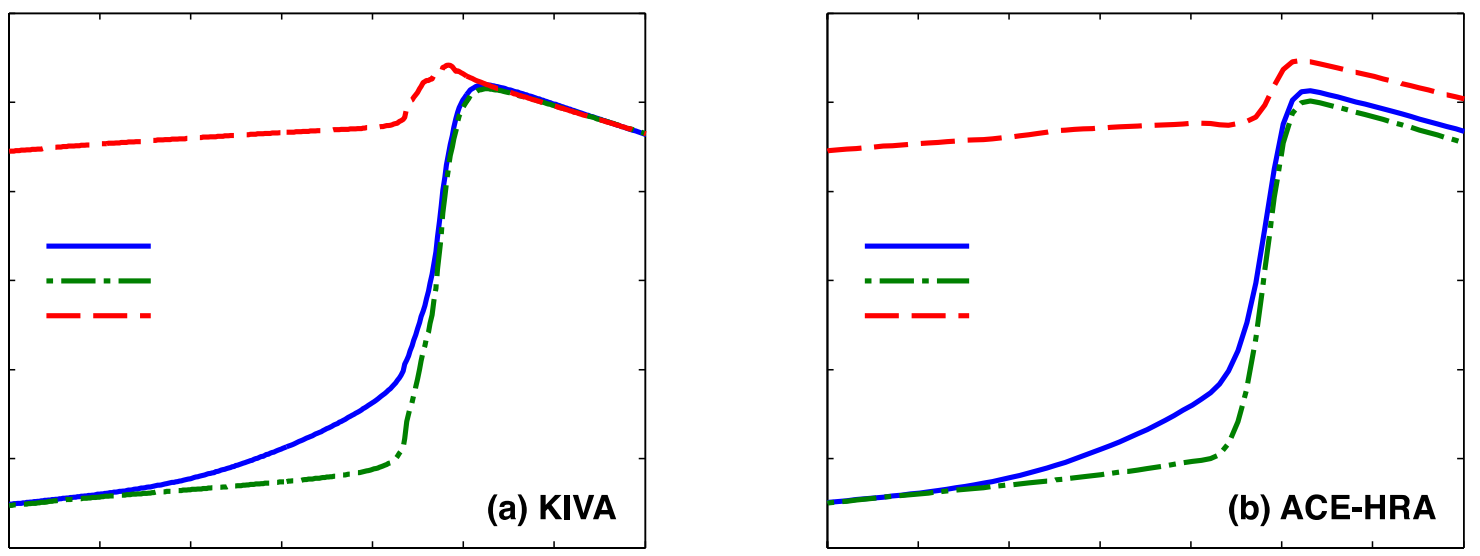

Figure 7. Comparison of (a) KIVA results for global or mean, end-gas, and post-flame zone temperatures for the SACI validation Case 2 with (b) ACE-HRA estimates using a two-zone model with prescribed flame propagation and end-gas auto-ignition burn rates. 


\section{(a) End-Gas Temperature}

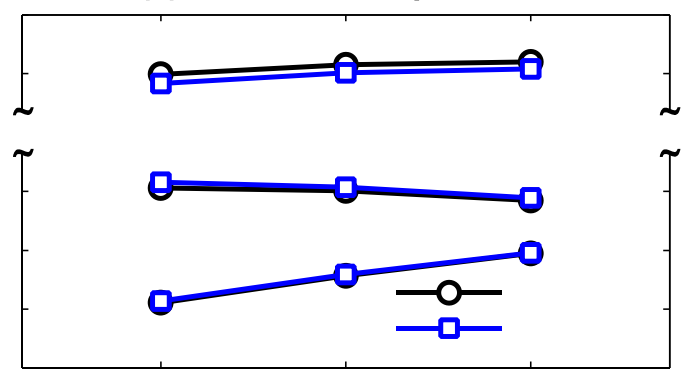

(b) Laminar Flame Speed, $S_{L}$

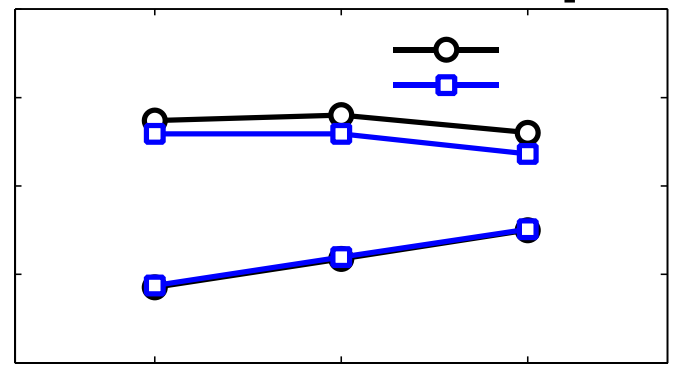

Figure 8. Comparison between KIVA and ACE-HRA predictions of (a) end-gas temperature at times of spark- $\left(\mathrm{T}_{\mathrm{EG}, \mathrm{SPK}}\right)$ and auto-ignition $\left(\mathrm{T}_{\mathrm{EG}, I \mathrm{IGN}}\right)$, and maximum end-gas temperatures $\left(\mathrm{T}_{\mathrm{EG}, \mathrm{MAX}}\right)$, and (b) laminar flame speed $\left(\mathrm{S}_{\mathrm{L}}\right)$ at times of spark and auto-ignition.

(a) Cumulative Heat Loss

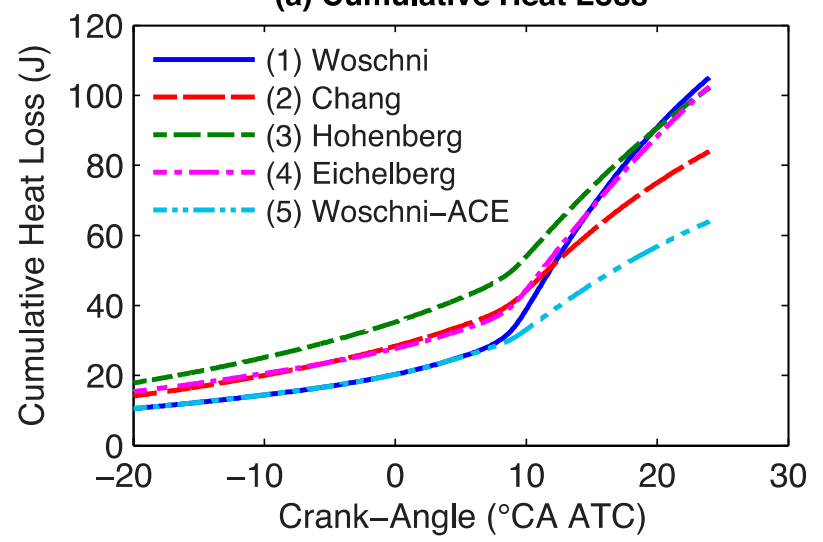

(b) Energy Balance

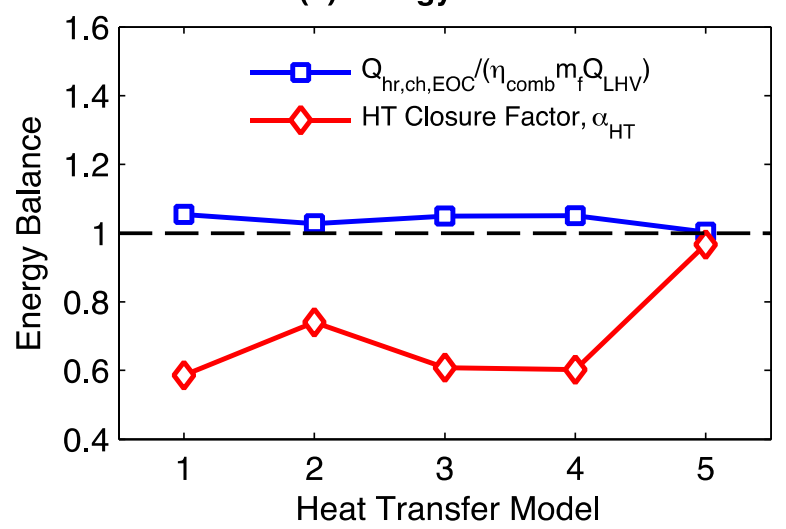

Figure 9. Comparison of different heat transfer correlations on (a) cumulative heat loss, and (b) energy balance and heat transfer energy closure factor $\alpha_{H T}$ for the SACI validation Case 2 in Table 3 . The heat transfer models (1 to 5) refer to the correlations listed in the legend of panel (a) and in Table 1, available for use in ACE-HRA. 


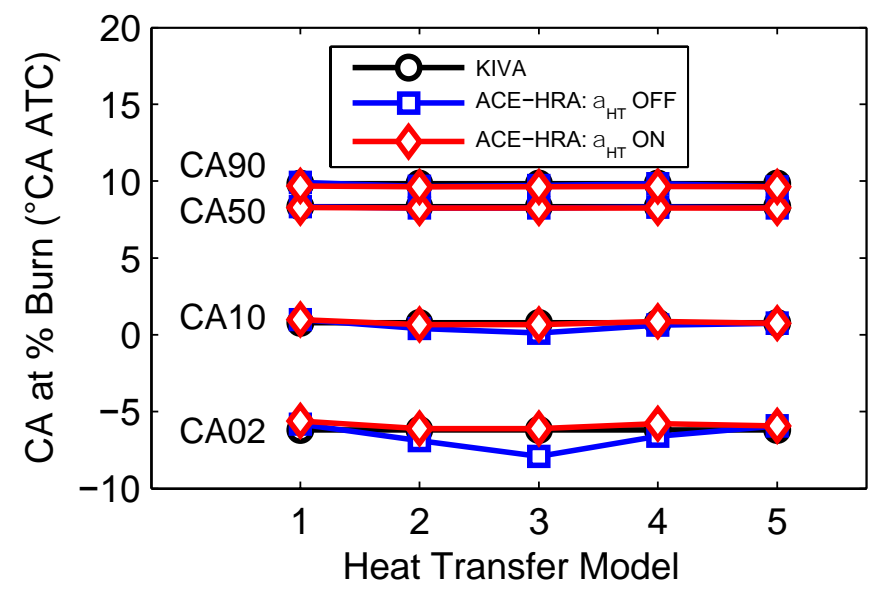

Figure 10. Comparison between KIVA and ACE-HRA predictions of SACI combustion phasing results, where the ACE-HRA results are provided with $\left(\alpha_{H T} \mathrm{ON}\right)$ and without $\left(\alpha_{H T} \mathrm{OFF}\right)$ forced energy closure. The heat transfer models (1 to 5) refer to the correlations listed in the legend of panel (a) of Figure 9 and in Table 1, available for use in ACEHRA.

(a) Cylinder Pressure

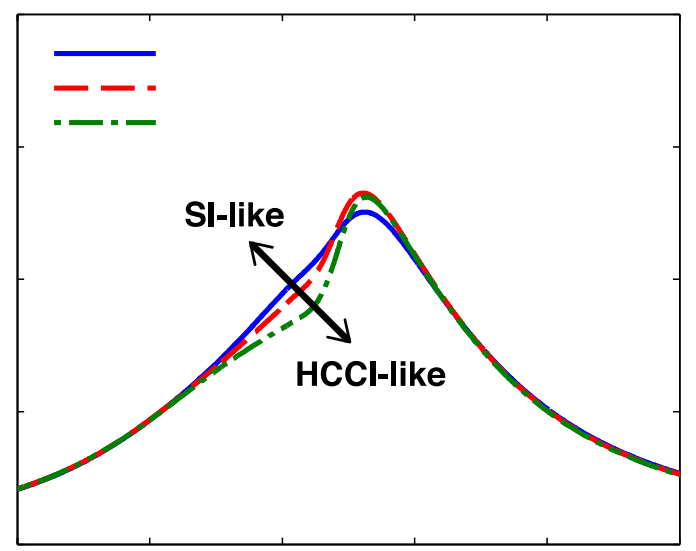

(b) Global RoHR

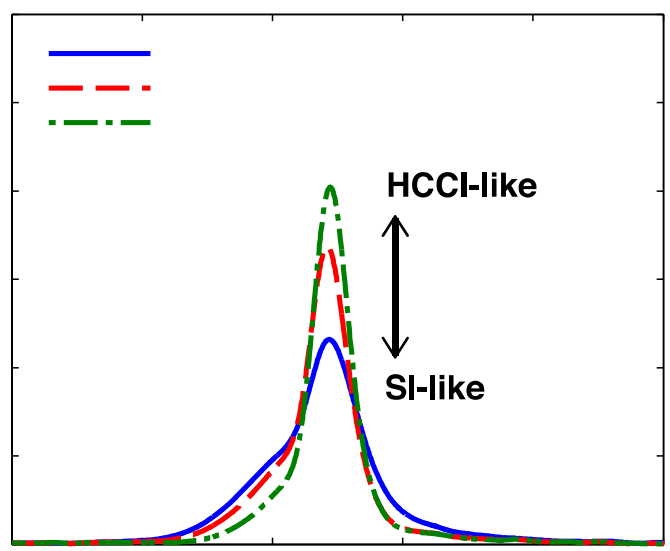

Figure 11. Ensemble-averaged (a) cylinder pressure and (b) RoHR over 200 consecutive cycles for three cases of the SACI study by Olesky et al. [52]. 
(a) Auto-Ignition \& Combustion Phasing

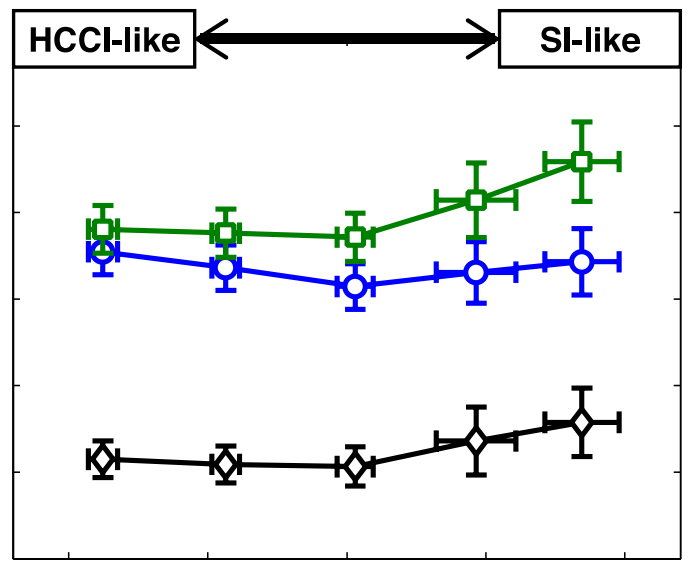

(b) Peak Burn Rate

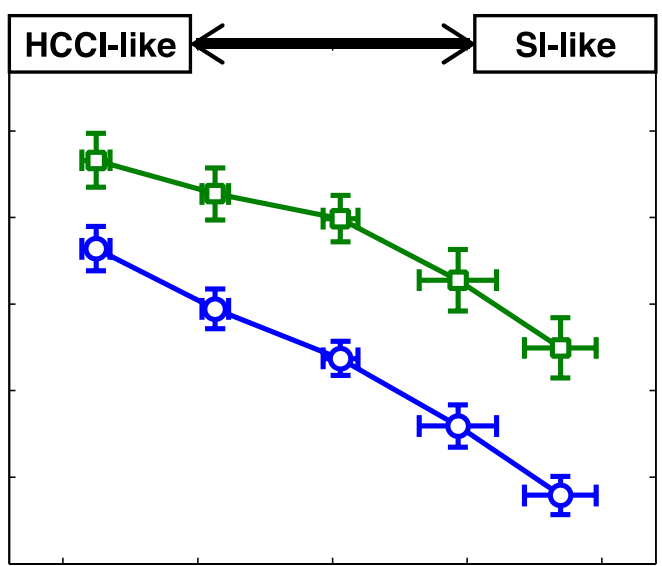

Figure 12. Results of advanced combustion analysis methods in ACE-HRA applied to the data of Figure 10 for (a) auto-ignition timing (CA-IGN), global combustion phasing (CA50), local end-gas (EG) combustion phasing (EG50); and for (b) peak global and local EG burn rate as a function of the burn fraction by flame. The error bars represent $25 \%$ of the standard deviation. 